\title{
Isolation of Single-Domain Antibody Fragments That Preferentially Detect Intact (146S) Particles of Foot-and- Mouth Disease Virus for Use in Vaccine Quality Control
}

\author{
Michiel M. Harmsen ${ }^{1 *}$, Julian Seago ${ }^{2}$, Eva Perez ${ }^{2}$, Bryan Charleston ${ }^{2}$, Phaedra L. Eblé \\ and Aldo Dekker ${ }^{1}$
}

${ }^{1}$ Wageningen Bioveterinary Research, Lelystad, Netherlands, ${ }^{2}$ The Pirbright Institute, Woking, United Kingdom

OPEN ACCESS

Edited by:

Kevin A. Henry,

National Research Council Canada,

Canada

Reviewed by:

Ming Yang,

Canadian Food Inspection

Agency, Canada

Mehdi Arbabi Ghahroudi,

National Research Council Canada

(NRC-CNRC), Canada

*Correspondence:

Michiel M. Harmsen

michiel.harmsen@wur.nI

Specialty section:

This article was submitted to Vaccines and Molecular

Therapeutics,

a section of the journal

Frontiers in Immunology

Received: 25 April 2017 Accepted: 26 July 2017 Published: 17 August 2017

Citation: Harmsen MM, Seago J, Perez E, Charleston B, Eblé PL and Dekker A (2017) Isolation of Single-Domain Antibody Fragments That Preferentially Detect Intact (146S)

Particles of Foot-and-Mouth Disease Virus for Use in Vaccine Quality Control. Front. Immunol. 8:960. doi: 10.3389/fimmu.2017.00960
Intact (146S) foot-and-mouth disease virus (FMDVs) can dissociate into specific (12S) viral capsid degradation products. FMD vaccines normally consist of inactivated virions. Vaccine quality is dependent on $146 \mathrm{~S}$ virus particles rather than $12 \mathrm{~S}$ particles. We earlier isolated two llama single-domain antibody fragments ( $\mathrm{VHHs}$ ) that specifically recognize $146 S$ particles of FMDV strain $\mathrm{O}_{1}$ Manisa and shown their potential use in quality control of FMD vaccines during manufacturing. These $146 \mathrm{~S}$-specific $\mathrm{VHHs}$ were specific for particular $O$ serotype strains and did not bind strains from other FMDV serotypes. Here, we describe the isolation of 146S-specific VHHs against FMDV SAT2 and Asia 1 strains by phage display selection from llama immune libraries. VHHs that bind both $12 \mathrm{~S}$ and $146 \mathrm{~S}$ particles were readily isolated but VHHs that bind specifically to $146 \mathrm{~S}$ particles could only be isolated by phage display selection using prior depletion for $12 \mathrm{~S}$ particles. We obtained one 146S-specific $\mathrm{VHH}-\mathrm{M} 332 \mathrm{~F}$-that binds to strain Asia 1 Shamir and several VHHs that preferentially bind $146 \mathrm{~S}$ particles of SAT2 strain SAU/2/00, from which we selected $\mathrm{VHH}$ M379F for further characterization. Both M332F and M379F did not bind FMDV strains from other serotypes. In a sandwich enzyme-linked immunosorbent assay (ELISA) employing unlabeled and biotinylated versions of the same VHH M332F showed high specificity for $146 \mathrm{~S}$ particles but M379F showed lower 146S-specificity with some cross-reaction with $12 \mathrm{~S}$ particles. These ELISAs could detect $146 \mathrm{~S}$ particle concentrations as low as 2.3-4.6 $\mathrm{\mu g} / \mathrm{l}$. They can be used for FMD vaccine quality control and research and development, for example, to identify virion stabilizing excipients.

Keywords: enzyme-linked immunosorbent assay, single-domain antibody, foot-and-mouth disease, virion stability, foot-and-mouth disease virion, vaccine quality control

\section{INTRODUCTION}

Foot-and-mouth disease (FMD) is an animal disease that is caused by a picornavirus, FMD virus (FMDV), which encompasses seven serotypes: A, O, C, Asia1, SAT1, SAT2, and SAT3. Infection with any one serotype does not produce significant humoral immunity against other serotypes. In FMD endemic areas vaccination is used as a preventive method (1). Due to differences in serotype prevalence in the field most vaccines are used for serotypes $\mathrm{O}$ and $\mathrm{A}$. Further vaccines generally are specific 
for Asia1 or SAT2 serotypes. Conventional FMD vaccines (2) are based on chemically inactivated FMDVs that are formulated with an adjuvant. FMD virions consist of an RNA molecule and a capsid composed of 60 copies each of VP1, VP2, VP3, and VP4 proteins (3). Intact virions sediment at $146 \mathrm{~S}$ in sucrose gradients. Some FMDV strains also produce empty capsids that lack the RNA molecule and sediment at 75S. Mild heating or incubation at $\mathrm{pH}$ below 6.5 leads to irreversible dissociation of $146 \mathrm{~S}$ or $75 \mathrm{~S}$ particles into stable $12 \mathrm{~S}$ particles that contain five copies each of VP1, VP2, and VP3. Dissociation into $12 \mathrm{~S}$ particles results in a strongly reduced immunogenicity (4-7).

Several methods have been developed to measure the concentration of $146 \mathrm{~S}$ particles of the crude FMDV antigen preparation used for vaccine preparation. This is traditionally measured by sucrose density gradient (SDG) centrifugation (8). Novel methods that are more easy to automate are based on size-exclusion high-performance liquid chromatography $(9,10)$ or lateral flow immunoassay (11). All these methods have the advantage of being suitable for all FMDV strains, but the disadvantage of low sensitivity, limited sample throughput, and inability to discriminate different vaccine strains in multivalent vaccines. Double antibody sandwich (DAS) enzyme-linked immunosorbent assays (ELISAs) using monoclonal antibodies (mAbs) were also developed for FMDV antigen quantification $(7,12-16)$. They are more sensitive, but often not specific for intact $146 \mathrm{~S}$ particles. Only two DAS ELISAs were specific for $146 \mathrm{~S}$ particles due to use of a mAb showing such specificity. They were suitable for detection of A or O serotype strains $(15,16)$. We have recently developed two DAS ELISAs using two recombinant llama singledomain antibody fragments (VHHs) that bind specifically to either $146 \mathrm{~S}$ particles or $12 \mathrm{~S}$ particles of strain $\mathrm{O}_{1}$ Manisa $(17,18)$. In each ELISA, the same VHH was used for coating as well as for detection of captured antigen using biotinylated VHH. The DAS ELISA employing 146S-specific VHH M170 was specific for particular $\mathrm{O}$ serotype strains, including strain $\mathrm{O}_{1}$ Manisa. The DAS ELISA employing 12S-specific VHH M3 could detect FMDV antigen of several A, O, and Asia 1 strains but not SAT2 strain. We were also able to measure $146 \mathrm{~S}$ particles of A and Asia 1 serotype strains employing the M3 DAS ELISA of heated and untreated samples (17). However, this latter ELISA approach is not suitable for detecting $146 \mathrm{~S}$ particles in the presence of higher concentrations of $12 \mathrm{~S}$ particles. An ELISA approach employing a $146 \mathrm{~S}$-specific $\mathrm{VHH}$ is therefore preferred. We here describe the isolation of two VHHs for specific detection of $146 \mathrm{~S}$ particles of strains Asia 1 Shamir and SAT2 SAU/2/00.

Many conventional $\mathrm{mAbs}$ against FMDV have been isolated in the past. Most of those mAbs bind to both $12 \mathrm{~S}$ and $146 \mathrm{~S}$ particles $(7,19-22)$. However, mAbs that specifically detect $146 \mathrm{~S}$ particles are rarely isolated $(15,16)$. VHHs against FMDV have recently been isolated $(23,24)$ without reporting their particle specificity. M170 is the only 146 S-specific VHH that is currently described (17). It was isolated by screening a panel of $24 \mathrm{VHHs}$ against strain $\mathrm{O}_{1}$ Manisa that were earlier isolated from llama immune libraries (25). It is not surprising that $146 \mathrm{~S}$-specific VHHs or $\mathrm{mAb}$ are rare since $12 \mathrm{~S}$ and $146 \mathrm{~S}$ particles share many epitopes.

VHHs are normally isolated by phage display selection from immunized llamas or dromedaries (26). One of the advantages of using VHHs for this purpose is the high functional diversity of immune libraries derived from heavy chain antibodies since random shuffling of antibody heavy and light chains does not occur. Phage display VHH immune libraries therefore contain VHHs with many different specificities. The isolation of rare specificities requires dedicated selection procedures. The removal from libraries of clones with unwanted cross-reaction to particular antigens can be accomplished by prior depletion of libraries on these antigens before performing selection of VHHs on the target antigen (27), although such depletion often is inefficient $(28,29)$. We here describe the selection of VHHs specific for $146 \mathrm{~S}$ particles by depletion on $12 \mathrm{~S}$ particles. We focus on VHHs specific for Asia 1 and SAT2 FMDV since 146S-specific VHHs or mAbs are not yet available for these serotypes.

\section{MATERIALS AND METHODS}

\section{mAbs, VHHs, and FMDV Antigens}

Monoclonal antibody 13A6 was raised against SAT1 Zimbabwe/89 that does not neutralize FMDV in vitro, cross-reacts to SAT2 Zimbabwe/86 and binds in a trypsin-sensitive manner in ELISA (30). VHHs were produced in baker's yeast as a fusion to the natural llama heavy-chain antibody long hinge region and a hexahistidine tag using vector pRL188 (25) and purified from culture supernatant using immobilized-metal affinity chromatography as described earlier. VHHs produced in this manner are indicated by the suffix "F." At least $20 \%$ of the VHH amount produced in this manner is dimerized through the single cysteine present at the C-terminus of the $\mathrm{VHH}$, immediately preceding the his6 tag. Both such monomeric and dimeric VHHs are useful for functional immobilization of VHHs to polystyrene surfaces by passive adsorption (31). Yeast-produced VHHs were biotinylated at a weight ratio of protein to biotin of 10 using amine-reactive sulfo- $N$-hydroxysuccinimide-LC-biotin (Pierce, Rockford, IL, USA). Buffer was exchanged to PBS and free biotin removed by at least three consecutive 10 -fold dilutions and concentration using Amicon Ultra 3-kDa molecular weight cutoff concentration devices (Millipore, Billerica, MA, USA). The VHH2 M3ggsVI4 ${ }_{\mathrm{Q} 6 \mathrm{E}}$ specific for $12 \mathrm{~S}$ particles has been previously described (32).

The FMD vaccine strains Asia 1 Shamir/Israel/89, SAT2 $\mathrm{SAU} / 2 / 00, \mathrm{O}_{1}$ Manisa/Turkey/69, $\mathrm{O}_{1}$ British Field Strain 1860 (BFS)/67, A Turkey/98, and $\mathrm{A}_{24}$ Cruzeiro/Brazil/55 were used for antigen production. FMDV antigen originated from the virus production facilities in Lelystad. FMDV was cultured using BHK21 cells grown in suspension in industrial size bioreactors. FMDV present in the clarified culture was inactivated with $0.01 \mathrm{M}$ binary ethylenimine and concentrated using two consecutive polyethylene glycol-6000 precipitations, resulting in crude antigen. Infectious FMDV was prepared at laboratory scale by growing them on monolayers of BHK-21 cells and harvesting the culture supernatant without further treatment. Work with infectious FMDV was done in a high containment unit at Wageningen Bioveterinary Research using appropriate measures for virus handling and waste disposal to prevent FMDV introduction into the environment. Wageningen Bioveterinary Research is authorized to work with live FMDV according to EU directive 2003/85/EC. 
Foot-and-mouth disease virus antigens were fractionated using $10-40 \%$ SDGs that were centrifuged for $2.5 \mathrm{~h}$ at $10^{\circ} \mathrm{C}$ and $200,000 \times g$. The gradients were fractionated into $200.61 \mathrm{ml}$ aliquots and the absorbance at $254 \mathrm{~nm}$ was determined to identify the $146 \mathrm{~S}$ peak. The $146 \mathrm{~S}$ concentration in milligrams per liter was then calculated by multiplying the absorbance at $254 \mathrm{~nm}$ with 126.7. $12 \mathrm{~S}$ particles were prepared from $146 \mathrm{~S}$ preparations by acidification $\left(12 \mathrm{~S}^{\mathrm{A}}\right)$ or heat treatment for $1 \mathrm{~h}$ at $56^{\circ} \mathrm{C}\left(12 \mathrm{~S}^{\mathrm{H}}\right)$ as previously described (33).

\section{Llama Immunization and Phage Library Construction}

Llama immunizations were performed after ethical review by Wageningen Bioveterinary Research and in accordance with Dutch national guidelines on animal use. The immunization of llama 6058 with crude antigen of FMDV strain Asia 1 Shamir has been described earlier (25). The immunization of llamas 3049 and 3050 with influenza antigens and subsequent phage library construction was earlier described (34). Simultaneously with these influenza antigens llamas 3049 and 3050 were immunized with FMDV $146 \mathrm{~S}$ particles purified from SDG. For each of the three immunizations llama 3049 received $40 \mu \mathrm{g}$ Asia 1 Shamir $146 \mathrm{~S}$ particles and $45 \mu \mathrm{g} \mathrm{A}_{24}$ Cruzeiro $146 \mathrm{~S}$ particles, whereas llama 3050 received $50 \mu$ g SAT2 SAU/2/00 146S particles. Phage display immune libraries in phagemid vector pRL144 (35) of at least $10^{7}$ independent clones were generated as previously described $(25,34)$.

\section{Phage Display Selection of Antigen Binding VHHs}

Phage display selections were performed by two consecutive rounds of biopanning (36) in polystyrene 96-well plates (Greiner, Solingen, Germany, Cat. No. 655092), using $100 \mu \mathrm{l} /$ well for each incubation. Many variations on the procedure were used (Table 1). In general, antigen was immobilized to 96-well plates at three serial 10 -fold dilutions and a control without antigen was included. VHHs were normally coated at concentrations of 1, 0.1, and $0.01 \mathrm{mg} / \mathrm{l}$ in $0.05 \mathrm{M}$ carbonate/bicarbonate buffer, $\mathrm{pH} 9.6$ (coating buffer), overnight at $4^{\circ} \mathrm{C}$. Purified $146 \mathrm{~S}$ particles $(1 \mathrm{mg} / \mathrm{l})$ were separately incubated in PBS buffer containing $1 \%$ milk and 0.05\% Tween-20 (PBSTM) for $1 \mathrm{~h}$ at room temperature (RT). Controls included wells coated with $\mathrm{VHH}$ without subsequent incubation with FMDV antigen and uncoated wells incubated with $1 \mathrm{mg} / \mathrm{l} \mathrm{FMDV}$ antigen. Plates were then incubated with $1 \times 10^{9}$ transducing phage units per well. In initial experiments, phages were preincubated in PBSTM containing $10 \mathrm{mg} / 1 \mathrm{l}^{\mathrm{A}}$ particles and then added to wells with captured $146 \mathrm{~S}$ particles to compete for binding to $12 \mathrm{~S}^{\mathrm{A}}$. In later experiments, phages binding to $12 \mathrm{~S}^{\mathrm{A}}$ particles were depleted prior to biopanning by incubation on plates containing immobilized $12 S^{A}$ particles. For this purpose, separate plates were coated with coating buffer containing $1 \mathrm{mg} / \mathrm{l} \mathrm{M} 3 g g s V I 4_{\mathrm{Q} 6 \mathrm{E}}$ or M311F specific for SAT2 $\mathrm{SAU} / 2 / 00$ antigen and subsequently incubated with $5 \mathrm{mg} / 1 \mathrm{l}^{\mathrm{A}}$ particles of strains Asia 1 Shamir or SAT2 SAU/2/00, respectively. Phages were then incubated on these plates with captured $12 \mathrm{~S}^{\mathrm{A}}$ particles after which the unbound phages were transferred

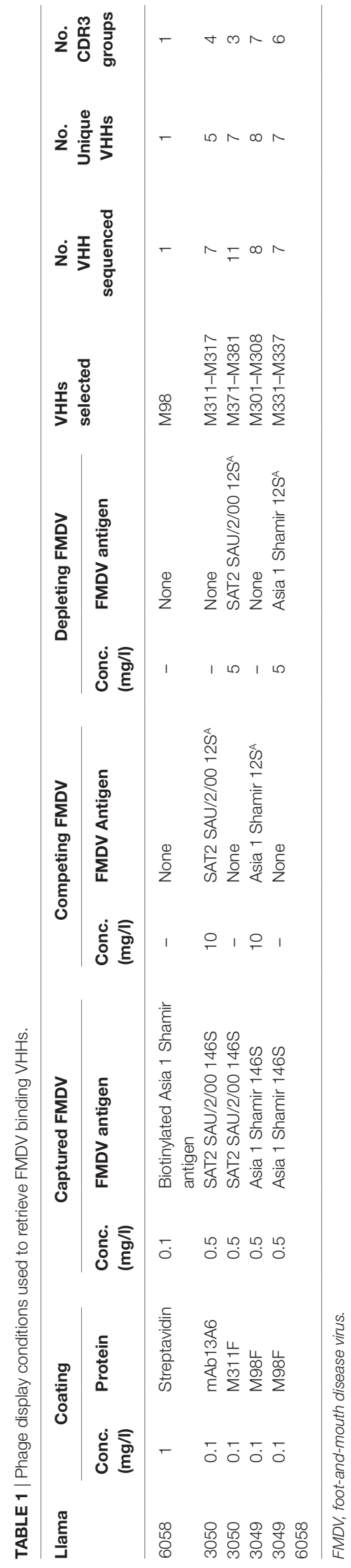


to biopanning plates containing captured $146 \mathrm{~S}$ particles. To ensure binding of most $12 S^{\mathrm{A}}$ reactive phages we used 20 -fold lower amounts of phage $\left(5 \times 10^{7}\right.$ transducing phage units per well) when employing depletion. Bound phages were finally eluted by incubation with $1 \mathrm{mg} / \mathrm{ml}$ trypsin in PBS for $30 \mathrm{~min}$ at $37^{\circ} \mathrm{C}$ and immediately transduced to Escherichia coli TG1 $\left[\left(\mathrm{F}^{\prime}\right.\right.$ traD36 proAB lacIqZ $\Delta$ M15) supE thi-1 $\Delta$ (lac-proAB) $\left.\Delta(m c r B-h s d S M) 5\left(r K^{-} m K^{-}\right)\right]$cells. In each selection round, we performed a phage ELISA simultaneous with the phage display selection for evaluation of the phage display selection. For this purpose, a duplex plate containing similar concentrations and types of antigen and phage was incubated with a peroxidaseconjugated mAb against M13 phage instead of incubation with trypsin. The amount of bound antigen-specific phage was then measured by phage ELISA.

\section{Production of Soluble VHH in E. coli}

After the second round of panning phages was transduced to E. coli TG1 cells, individual colonies were picked and the VHH genes were induced with $1 \mathrm{mM}$ isopropyl $\beta$-D-thiogalactopyranoside. Recombinant VHHs, extracted from the periplasm, were tested for binding to FMDV antigens at 10-fold dilution as described below in Section "Enzyme-Linked Immunosorbent Assays."

\section{Sequence Analysis}

Sequence analysis of the $\mathrm{VHH}$ encoding region was performed, as previously described (37). The deduced VHH amino acid sequences were aligned according to the IMGT system (38) for alignment, numbering, and complementarity-determining region definition of immunoglobulins. VHHs were classified into subfamilies as earlier defined (37). Potential N-glycosylation sites were defined as Asn-X-Ser/Thr, where X represents any amino acid, except Pro.

\section{Enzyme-Linked Immunosorbent Assays}

Three different ELISA procedures were used. We first describe the basic ELISA procedure that was commonly used in these three procedures. ELISAs were performed by coating high-binding polystyrene 96 -well plates (Greiner) with $0.1-1 \mathrm{mg} / \mathrm{l}$ of unlabeled $\mathrm{VHH}, \mathrm{VHH} 2$, or $\mathrm{mAb}$ in $50 \mathrm{mM}$ carbonate/bicarbonate buffer, $\mathrm{pH} 9.6$ (coating buffer), overnight at $4^{\circ} \mathrm{C}$. Coating and subsequent incubations were performed using $100 \mu \mathrm{l}$ per well. After washing, the coated plates were incubated with FMDV antigens in ELISAbuffer (1\% skimmed milk; 0.05\% Tween-20; $0.5 \mathrm{M} \mathrm{NaCl} ; 2.7 \mathrm{mM}$ $\mathrm{KCl} ; 2.8 \mathrm{mM} \mathrm{KH} \mathrm{PO}_{4} ; 8.1 \mathrm{mM} \mathrm{Na}_{2} \mathrm{HPO}_{4}$; $\mathrm{pH}$ 7.4) or PBSTM for $1 \mathrm{~h}$ at RT. The $146 \mathrm{~S}$ concentration of the FMDV antigens was determined by measuring the absorbance at $254 \mathrm{~nm}$ as described above. The concentration of the $12 \mathrm{~S}$ antigens was derived from the $146 \mathrm{~S}$ concentration of the sample from which it was prepared assuming complete conversion of $146 \mathrm{~S}$ into $12 \mathrm{~S}$ particles. Plates were next incubated with either phage-displayed VHH, E. coliproduced $\mathrm{VHH}$, or yeast-produced biotinylated $\mathrm{VHH}$, and subsequently with a suitable specific peroxidase conjugate, using the same buffer as used for incubation with FMDV antigen (ELISAbuffer or PBSTM). The peroxidase conjugate was subsequently detected by staining with 3,3',5,5'-tetramethylbenzidine. After stopping the reaction by addition of $0.5 \mathrm{M} \mathrm{H}_{2} \mathrm{SO}_{4}(50 \mu \mathrm{l}$ per well) the absorbance at $450 \mathrm{~nm}$ was measured using a Multiskan Ascent spectrophotometer (Thermo Labsystems, Helsinki, Finland).

For phage ELISA plates were preferably coated with low concentrations of VHH $(0.1 \mathrm{mg} / \mathrm{l})$ and FMDV antigen $(0.5 \mathrm{mg} / \mathrm{l})$ as described in Table 1. Many variations on the procedure were used during phage display selection as described above. Bound phage displayed $\mathrm{VHH}$ was detected by incubation with peroxidaseconjugated $\mathrm{mAb}$ against the M13 $\mathrm{p} 8$ coat protein (GE Healthcare, Little Chalfont, UK) in PBSTM.

For ELISA using E. coli-produced soluble VHH plates were preferably coated with $1 \mathrm{mg} / \mathrm{l} \mathrm{VHH}$ and then subsequently incubated with $1 \mathrm{mg} / \mathrm{l} \mathrm{FMDV}$ antigen in ELISA buffer. Bound FMDV antigens were detected by incubation with 10 -fold diluted E. coli-produced soluble $\mathrm{VHH}$, which contains a myc-tag, and a peroxidase-conjugated mAb against the c-myc tag (clone 9E10; Roche Applied Science).

For DAS ELISA to measure the FMDV antigen concentration plates were coated with $0.5 \mathrm{mg} / \mathrm{l}$ of unlabeled $\mathrm{VHH}$ or $\mathrm{VHH} 2$. These plates were then incubated with serial 2-fold dilution series of FMDV antigen preparations in ELISA buffer. Normally, standards of untreated FMDV antigen were included in the ELISAs for quantification of $146 \mathrm{~S}$ particles. However, $12 \mathrm{~S}^{\mathrm{A}}$ preparations of FMDV antigen were used as standards in the ELISA employing M3ggsVI-4 $4_{\mathrm{Q} 6 \mathrm{E}}$. Standards were serial twofold dilutions of $1 \mathrm{mg} / \mathrm{l}$ start concentration. Plates were next incubated with $0.25 \mathrm{mg} / \mathrm{l}$ of biotinylated $\mathrm{VHH}(2)$. Bound biotinylated $\mathrm{VHH}(2)$ was detected with $1 \mathrm{mg} / \mathrm{l} \mathrm{PO-conjugated} \mathrm{streptavidin} \mathrm{(Jackson}$ ImmunoResearch Laboratories Inc., West Grove, PA, USA). Absorbance data were evaluated using an Excel $^{\circledR}$ spreadsheet template (Microsoft Corporation, Redmond, WA, USA). A fourparameter logistic curve was fitted to absorbance and FMDV antigen concentrations of standards by non-linear least squares using the Excel ${ }^{\circledR}$ solver tool. The FMDV antigen concentration in unknown samples was then determined by interpolation. For determination of the quality of binding of VHHs to particular FMDV antigens these antigens were titrated in twofold dilution series. The effective antigen concentration required to reach a particular absorbance value was then interpolated after four-parameter logistic curve fitting of absorbance and antigen concentrations.

The limit of detection (LOD) of ELISAs was measured by titrating FMDV antigens in triplicate and interpolating the $\mathrm{VHH}$ concentration required to reach the average and three times the $\mathrm{SD}$ of nine blank measurements without antigen.

\section{RESULTS}

\section{Selection of 146S-Specific VHHs}

We earlier immunized llama 6058 with crude antigen of FMDV strains $\mathrm{O}_{1}$ Manisa, A Turkey, $\mathrm{A}_{22}$ Iraq, and Asia 1 Shamir. We isolated many $\mathrm{FMDV}_{1}$ Manisa binding VHHs from this llama by phage display employing biotinylated FMDV antigen captured with streptavidin-coated magnetic beads (25). The VHH M98 was similarly selected from llama 6058 using biotinylated FMDV Asia 1 Shamir antigen. Yeast-produced M98F VHH neutralized Asia 1 Shamir FMDV in vitro, confirming M98F binds FMDV 
virions rather than a host protein present in the crude FMDV antigen used to perform the selection. As further confirmed below M98F was found to bind both $12 \mathrm{~S}$ and $146 \mathrm{~S}$ particles. This was not unexpected since $146 \mathrm{~S}$-specific VHHs were also rarely retrieved during phage display selection of $\mathrm{O}_{1}$ Manisa binding VHHs (25).

To improve the selection process of $146 \mathrm{~S}$-specific VHHs we purified $146 \mathrm{~S}$ particles by SDGs. The purified 146S particles were then used for both novel llama immunization and phage display selection of VHHs. One llama (3049) was immunized with FMDV Asia 1 Shamir 146S and another llama (3050) with SAT2 SAU/2/00 146S. As observed with many other proteins (39) FMDV loses much of its antigenicity upon direct passive adsorption to polystyrene (40). We, therefore, used M98F VHH that binds Asia 1 Shamir and mAb 13A6 that binds SAT2 SAU/2/00 to capture purified $146 \mathrm{~S}$ particles in ELISA. We initially tried to select VHHs that bind specifically to $146 \mathrm{~S}$ particles by competition during phage display selection with a surplus of $12 \mathrm{~S}^{\mathrm{A}}$ particles. This approach was not successful as all VHHs isolated bound both $146 \mathrm{~S}$ and $12 \mathrm{~S}^{\mathrm{A}}$ particles when tested as soluble $\mathrm{VHH}$ produced from $E$. coli TG1 cells (results not shown). After sequence analysis (Table 1), we identified five unique clones (M311-M317) binding SAT2 SAU/2/00 and eight unique clones (M301-M308) binding Asia 1 Shamir 146S. Their cross-reaction with 12S was later confirmed using yeast-produced VHH (Table 2). To increase enrichment of 146S-specific VHHs we improved phage display selections in two ways. Since mAb $13 \mathrm{~A} 6$ preferentially binds $12 \mathrm{~S}^{\mathrm{A}}$ particles (see below), it was replaced by a novel isolated $\mathrm{VHH}$ that was highly produced in yeast, M311F, for capture of SAT2 SAU/2/00 146S particles. Furthermore, novel selections were performed using depletion with immobilized $12 \mathrm{~S}^{\mathrm{A}}$ particles instead of competition with soluble $12 \mathrm{~S}^{\mathrm{A}}$ particles. Using these novel selection procedures we retrieved seven unique SAT2 SAU/2/00 binding VHHs comprising three novel CDR3 groups (Table 1) that are different from earlier isolated SAT2 SAU/2/00 binding VHHs (Table 2) and seven unique Asia 1 Shamir binding VHHs comprising six CDR3 groups (Table 1) that are mostly different from earlier isolated VHHs (Table 2).

\section{S Specificity of VHHs}

Seventeen VHHs with different CDR3 sequences (Table 2) were produced by yeast expression. They all lacked potential $N$-glycosylation sites to prevent compromised antigen binding due to fortuitous $\mathrm{N}$-glycosylation. The purified VHHs were biotinylated for use in DAS ELISA in combination with the same unlabeled VHH for coating. To assess the specificity of the biotinylated VHHs for the different FMDV particles we performed DAS-ELISAs with a titration series of untreated antigen, 146S particles and $12 \mathrm{~S}^{\mathrm{H}}$. Similar to earlier methods (17), the FMDV antigen concentration required to reach an absorbance value of 0.4 was calculated for each FMDV antigen. The absorbance value of 0.4 was chosen because for all different ELISAs used it is sufficiently above background absorbance values to be indicative of antigen binding and sufficiently below the maximal absorbance value. The ratio between these antigen concentration values for $12 \mathrm{~S}^{\mathrm{H}}$ and $146 \mathrm{~S}$ was taken as a measure for particle

TABLE 2 | VHH sequence characteristics and specificity of VHHs for $12 \mathrm{~S}$ and $146 \mathrm{~S}$ particles in DAS ELISA using the same VHH for coating and as biotinylated VHH.

\begin{tabular}{|c|c|c|c|c|c|c|c|}
\hline \multirow[t]{2}{*}{ VHH or mAb } & \multirow[t]{2}{*}{ Llama } & \multirow[t]{2}{*}{ CDR3 sequence } & \multirow[t]{2}{*}{ VHH subfamilya } & \multicolumn{3}{|c|}{$\begin{array}{c}\text { Antigen concentration }(\mu \mathrm{g} / \mathrm{l}) \text { to reach } \\
\text { absorbance }=0.4\end{array}$} & \multirow[t]{2}{*}{ Ratio $12 \mathrm{~S}^{\mathrm{H}} / 146 \mathrm{~S}$} \\
\hline & & & & antigen & $146 S$ & $12 S^{H}$ & \\
\hline M311F & 3050 & NAITYYTDAPDY & 2 & 2.7 & 2.2 & 5.7 & 2.6 \\
\hline M314F & 3050 & AADKWLYISGWRHCRPVFGS & 3 & 8.3 & 20 & 17 & 0.85 \\
\hline M315F & 3050 & YGDIRVRNY & 2 & 5.7 & 3.6 & 17 & 4.7 \\
\hline M379F & 3050 & NLVNWGYGENY & 2 & 1.8 & 1.2 & 34 & 28 \\
\hline M380F & 3050 & NYQRPLSNDNY & 2 & 0.70 & 0.59 & 8.7 & 15 \\
\hline mAb $13 A 6$ & $N A^{b}$ & NA & NA & $>1,000^{\circ}$ & $>1,000$ & 164 & $<0.16$ \\
\hline \multicolumn{8}{|l|}{ Asia 1 Shamir } \\
\hline M98F & 6058 & AAQSPGMSGTYSRSDVYPY & 1 & 4.1 & 5.5 & 29.8 & 5.4 \\
\hline M301F & 3049 & AATEDYYSGSLGSYYVCPDYYNMDY & 3 & 60 & 67 & $>1,000$ & $>15$ \\
\hline M308F & 3049 & AGDQDPAYCSDYWDLNEYDY & 3 & 39 & 55 & $>1,000$ & $>18$ \\
\hline M332F & 3049 & AAAWSFRSDYGARLKSAYDF & 1 & 8.4 & 7.6 & 433 & 57 \\
\hline M334F & 3049 & AADDSGLHGCSDYWILYEYEY & 3 & 245 & 342 & $>1,000$ & $>2.9$ \\
\hline M336F & 6058 & AAEESWSTSTYYYTHSYSY & 1 & $>1,000$ & $>1,000$ & $>1,000$ & ND \\
\hline$M 3 g g s V \mid 4_{Q 6 E}$ & NA & NA & NA & 51 & 746 & 13 & 0.017 \\
\hline
\end{tabular}

${ }^{a}$ As defined by reference (37).

${ }^{b} \mathrm{NA}$, Not applicable.

${ }^{c}>1,000$ indicates absorbance does not exceed 0.4 at the highest VHH concentration analyzed (1 mg/l).

DAS, double antibody sandwich; ELISAs, enzyme-linked immunosorbent assays; mAb, monoclonal antibody. 
specificity (Table 2 ). A ratio $>1$ corresponds to $146 \mathrm{~S}$ specificity and a ratio $<1$ corresponds to $12 \mathrm{~S}$ specificity.

In the case of SAT2 SAU/2/00 antigen mAb $13 \mathrm{~A} 6$ shows $12 \mathrm{~S}$ specificity with a ratio below 0.16 , the four VHHs selected by competition with $12 \mathrm{~S}^{\mathrm{A}}$ show no or limited $146 \mathrm{~S}$ specificity with ratios of $0.85-4.7$, whereas the three VHHs selected by depletion with $12 S^{\mathrm{A}}$ (M377F, M379F and M380F) show higher 146S specificity with ratios of 10-28 (Table 2). M379F exhibited the highest $146 \mathrm{~S}$ specificity and recognized relatively low antigen and $146 \mathrm{~S}$ concentrations as compared to other SAT2 SAU/2/00 binding VHHs. Among the Asia 1 Shamir binding VHHs, $\mathrm{M} 332 \mathrm{~F}$ that was selected by depletion on $12 \mathrm{~S}^{\mathrm{A}}$ particles showed highest $146 \mathrm{~S}$ specificity with a ratio of 57 . Furthermore, M332F recognized lower concentrations of untreated antigen and 146S as compared to most of the other nine VHHs. Only M311F recognized slightly lower antigen concentrations, although with far lower $146 \mathrm{~S}$ specificity (Table 2). In conclusion, M332F exhibited high 146S specificity for strain Asia 1 Shamir, whereas M379F showed some 146 S specificity for strain SAT2 $\mathrm{SAU} / 2 / 00$.

We next titrated FMDV antigens and $12 \mathrm{~S}^{\mathrm{H}}$ of strains SAT2 $\mathrm{SAU} / 2 / 00$ and Asia 1 Shamir in triplicate in the M3ggsVI4 ${ }_{\mathrm{Q} 6 \mathrm{E}}$, M311F, M379F, M98F, and M332F ELISAs using the same VHH as used for detection also for coating. The LOD was calculated for each ELISA (Table 3). The M332F ELISA had an LOD of $4.6 \mu \mathrm{g} / \mathrm{l}$ and the M379F ELISA of $2.3 \mu \mathrm{g} / \mathrm{l}$ for antigen. We also titrated the antigens in these latter two ELISAs in the presence of a constant amount of $12 \mathrm{~S}^{\mathrm{H}}$ particles to determine if antigen quantification is affected by the presence of $12 \mathrm{~S}^{\mathrm{H}}$ particles. Asia 1 Shamir antigen quantification in the M332F ELISA was not affected by the pres-

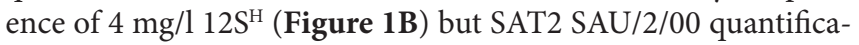
tion in the M379F ELISA was affected already by the lowest $12 \mathrm{~S}^{\mathrm{H}}$ concentration analyzed $(0.15 \mathrm{mg} / \mathrm{l}$; Figure 1E). This is consistent with the earlier observed higher specificity of M332F for $146 \mathrm{~S}$ particles than M379F.

\section{FMDV Strain Specificity}

To further characterize the 17 VHHs, their respective ability to bind to strains of other FMDV serotypes was investigated. As a control we included mAb $13 \mathrm{~A} 6$ and M8ggsVI4 $4_{\mathrm{Q} 6 \mathrm{E}}$, to demonstrate successful immobilization of the various antigens (Table 4). All seven SAT2 SAU/2/00 binding VHHs did not cross-react to strains Asia 1 Shamir, A Turkey, $\mathrm{A}_{24}$ Cruzeiro, $\mathrm{O}_{1} \mathrm{BFS}$, or $\mathrm{O}_{1}$

TABLE 3 | LOD of different DAS ELISAs.

\begin{tabular}{llcc}
\hline \multirow{2}{*}{ FMDV strain } & DAS ELISA & \multicolumn{2}{c}{ LOD $(\boldsymbol{\mu g} / \mathbf{l})$} \\
\cline { 3 - 4 } & & Antigen & $\mathbf{1 2 S}^{\mathbf{H}}$ \\
\hline SAT2 SAU/2/00 & M311F & 5.2 & 12 \\
SAT2 SAU/2/00 & M379F & 2.3 & 19 \\
Asia 1 Shamir & M98F & 3.8 & 19 \\
Asia 1 Shamir & M332F & 4.6 & $>2,000^{\circ}$ \\
Asia 1 Shamir & M3ggsVI4466E & 17 & 83 \\
\hline
\end{tabular}

${ }^{a}>2,000$ indicates $L O D$ not reached at the highest $V H H$ concentration used (2 mg/l). $D A S$, double antibody sandwich; ELISAs, enzyme-linked immunosorbent assays; LOD, limit of detection.
Manisa. Similarly, all 10 Asia 1 Shamir binding VHHs did not cross-react to strains SAT2 SAU/2/00, A Turkey, $\mathrm{A}_{24}$ Cruzeiro, $\mathrm{O}_{1}$ BFS, or $\mathrm{O}_{1}$ Manisa (Table 4).

\section{Binding to $12 S, 75 S$, and 146 S Particles in SDGs}

Next, we analyzed the specificity of M332F and M379F, as well as the earlier isolated M170F, for different FMDV particles (12S, $75 \mathrm{~S}$, and 146S) present in SDG fractions. As controls, we also analyzed each fraction using VHHs that detect both $12 \mathrm{~S}$ and $146 \mathrm{~S}$ particles of Asia 1 Shamir, SAT2 SAU/2/00, or $\mathrm{O}_{1}$ Manisa.

When FMDV Asia 1 Shamir, SAT2 SAU/2/00, or $\mathrm{O}_{1}$ Manisa purified $146 \mathrm{~S}$ particles were again separated on SDG a peak was seen in fractions $15-18$ that corresponds to $146 \mathrm{~S}$ particles (Figures 2A-C). The absence of further peaks indicated virions had not dissociated into smaller particles during virus handling. The peak in fraction 20 of Asia 1 Shamir FMDV (Figure 2A) probably represents aggregated $146 \mathrm{~S}$ particles. When $146 \mathrm{~S}$ particles purified from SDG were acidified and again subjected to SDG only fractions 2-5 contained FMDV antigen (Figures 2D-F), indicating full conversion into $12 \mathrm{~S}^{\mathrm{A}}$ particles. When crude antigen was separated on SDG some antigenic material was detected in fractions $6-14$ by ELISA (Figures 2G-I). This could represent $75 \mathrm{~S}$ particles that sediment between $12 \mathrm{~S}^{\mathrm{A}}$ and $146 \mathrm{~S}$ particles, although $75 \mathrm{~S}$ particles would be expected to form a sharper peak. The amount of putative $75 \mathrm{~S}$ particles as compared to $146 \mathrm{~S}$ particles is especially high for strain Asia 1 Shamir (Figure 2G), somewhat lower but still considerable for strain SAT2 SAU/2/00 (Figure 2H) and quite low, but clearly detectable for strain $\mathrm{O}_{1}$ Manisa (Figure 2I). To visualize the low amount of putative $75 \mathrm{~S}$ particles of strain $\mathrm{O}_{1}$ Manisa the material in fractions 1-15 was plotted on a scale of $0-0.5 \mathrm{mg} / \mathrm{l}$ on the right axis (Figure 2I). When crude antigen was acidified prior to SDG fractionation a $12 \mathrm{~S}$ peak was readily observed for Asia 1 Shamir (Figure 2J) and $\mathrm{O}_{1}$ Manisa (Figure 2L), but was less evident for SAT2 SAU/2/00 (Figure 2K). This could have been due to a combination of reduced $12 S^{A}$ particle reactivity in the M311F ELISA and the use of untreated antigen that predominantly consisted of $146 \mathrm{~S}$ particles as a standard. Acidified $\mathrm{O}_{1}$ Manisa antigen consisted only of $12 S$ particles, indicating full dissociation of $146 \mathrm{~S}$ and $75 \mathrm{~S}$ particles into $12 \mathrm{~S}$ (Figure 2L). However, acidified SAT2 SAU/2/00 antigen also contained a broad peak in the fractions corresponding to $75 \mathrm{~S}$ particles (Figure 2K), whereas Asia 1 Shamir antigen contained both a broad peak corresponding to putative $75 \mathrm{~S}$ particles as well as a $146 \mathrm{~S}$ peak, although both peaks were considerably lower as compared to untreated antigen (Figure 2J). This indicates that, unlike SDG purified 146 S particles, 75 S and 146 S particles present in Asia 1 Shamir crude antigen, and $75 \mathrm{~S}$ particles present in SAT2 SAU/2/00 antigen are only partially converted into $12 \mathrm{~S}$ by acidification. Such a difference in acid liability between SDG purified and crude antigen could be due to matrix effects due to different buffer composition, as was also reported earlier (41).

The M170F DAS ELISA detects only $\mathrm{O}_{1}$ Manisa $146 \mathrm{~S}$ particles (Figures 2C,F,I,L). The M332F DAS ELISA detects both Asia 1 Shamir $146 \mathrm{~S}$ and the putative $75 \mathrm{~S}$ particles, although the latter are detected with reduced efficiency as compared to the M98F DAS 


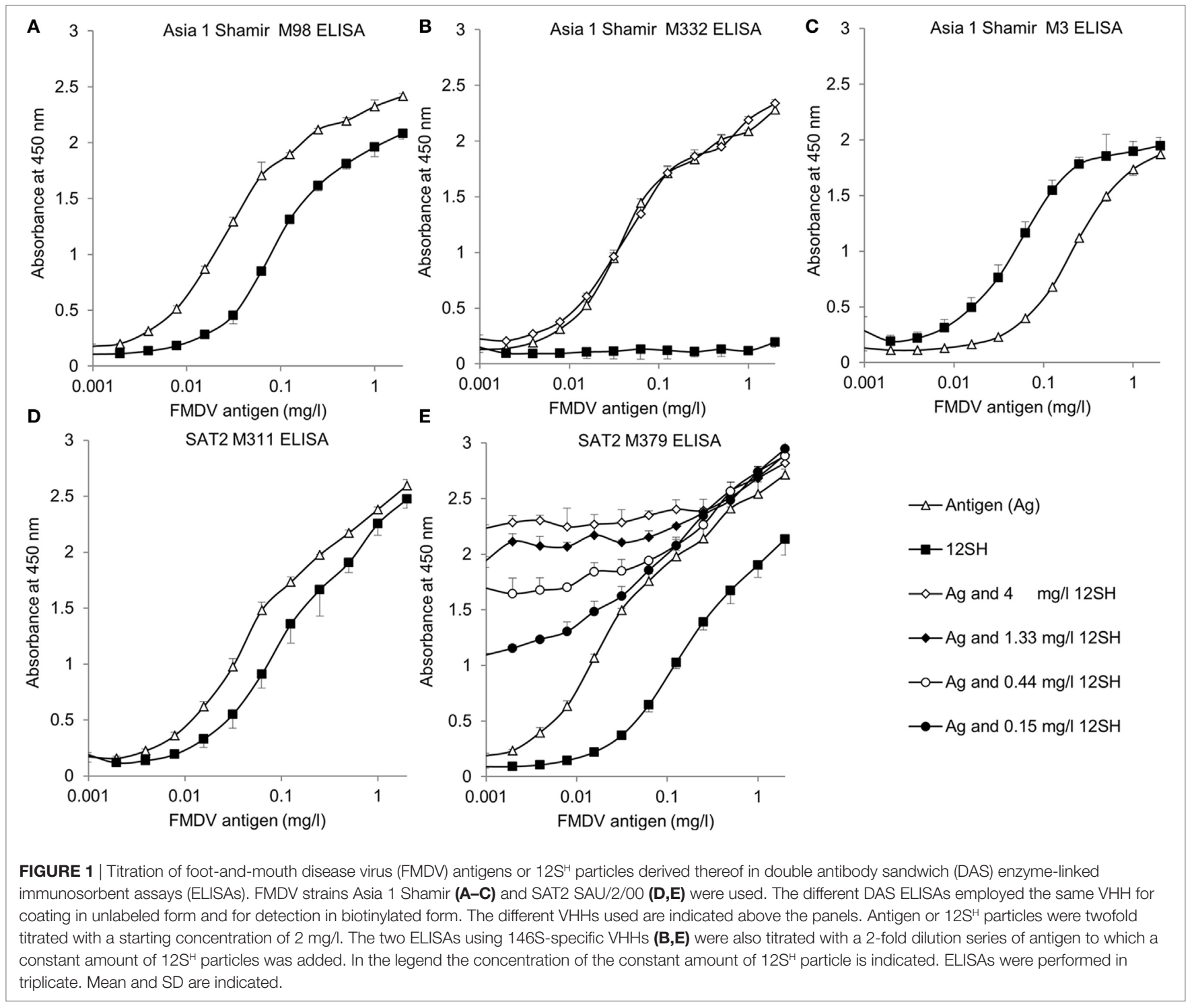

ELISA (Figures 2A,D,G,J). The M379F DAS ELISA detects both SAT2 SAU/2/00 146S and putative 75S particles with an efficiency that is equal to the M311F DAS ELISA, whereas SAT2 SAU/2/00 $12 S^{A}$ particles are detected with reduced efficiency as compared to the M311F ELISA (Figures 2B,E,H). The binding of M379F to $12 \mathrm{~S}^{\mathrm{A}}$ particles, although with reduced efficiency compared to $146 \mathrm{~S}$ particles, is consistent with the relatively low $146 \mathrm{~S}$ specificity observed for M379F.

To elucidate the nature of the putative $75 \mathrm{~S}$ particles we fractionated infectious FMDV on SDG and determined the presence of infectious virus in each fraction by plaque assay. In addition, we determined the concentration of total FMDV antigen present in each fraction by M3 ELISA after acidification. The M3 ELISA facilitates reliable quantification of $12 \mathrm{~S}, 75 \mathrm{~S}$, and $146 \mathrm{~S}$ particles against a $12 \mathrm{~S}$ standard. This analysis was only done for strains Asia 1 Shamir and $\mathrm{O}_{1}$ Manisa since strain SAT2 SAU/2/00 is not detected by M3 ELISA (Figures 3A,B). Notably, FMDV $\mathrm{O}_{1}$ Manisa infectious virus contained a considerable putative $75 \mathrm{~S}$ peak (Figure 3B). Infectious virus was only found in fractions 16-19, consistent with the notion that this represents $146 \mathrm{~S}$ particles and that FMDV antigen in fractions 9-11 represent 75S particles.

\section{DISCUSSION}

We aimed to isolate VHHs that specifically bind to FMDV $146 \mathrm{~S}$ particles of strains SAT2 SAU/2/00 and Asia 1 Shamir. For this purpose, llamas 3049 and 3050 were immunized with SDG purified $146 \mathrm{~S}$ particles of these strains. We preferentially used a $12 \mathrm{~S}$ depletion step in phage display selections to enrich for $146 \mathrm{~S}$-specific VHHs. In this manner, we isolated three novel SAT2 SAU/2/00 binding VHHs showing reasonable $146 \mathrm{~S}$ specificity and one novel Asia 1 Shamir binding VHH showing high $146 \mathrm{~S}$ specificity. However, when using a depletion step there is some risk of detachment of captured $12 \mathrm{~S}$ particles and carryover of this material into the wells containing $146 \mathrm{~S}$ 
TABLE 4 | Binding of biotinylated VHHs to different FMDV strains.

\begin{tabular}{|c|c|c|c|c|c|c|}
\hline \multirow[t]{2}{*}{ Biotinylated VHH(2) or mAb } & \multicolumn{6}{|c|}{ VHH concentration $(\mu \mathrm{g} / \mathrm{l})$ to reach absorbance of 0.4} \\
\hline & SAT2 SAU/2/00a & Asia 1 Shamir ${ }^{b}$ & A Turkeyc & $\mathrm{A}_{24}$ Cruzeiro $^{c}$ & $\mathrm{O}_{1} \mathrm{BFS}^{\mathrm{d}}$ & O $_{1}$ Manisa $^{d}$ \\
\hline M311F & 0.25 & $>1,000^{\circ}$ & $>1,000$ & $>1,000$ & $>1,000$ & $>1,000$ \\
\hline M314F & 2.8 & $>1,000$ & $>1,000$ & $>1,000$ & $>1,000$ & $>1,000$ \\
\hline M315F & 0.27 & $>1,000$ & $>1,000$ & $>1,000$ & $>1,000$ & $>1,000$ \\
\hline M317F & 0.06 & $>1,000$ & $>1,000$ & $>1,000$ & $>1,000$ & $>1,000$ \\
\hline M377F & 1.6 & $>1,000$ & $>1,000$ & $>1,000$ & $>1,000$ & $>1,000$ \\
\hline M379F & 0.29 & $>1,000$ & $>1,000$ & $>1,000$ & $>1,000$ & $>1,000$ \\
\hline M380F & 1.6 & $>1,000$ & $>1,000$ & $>1,000$ & $>1,000$ & $>1,000$ \\
\hline mAb $13 A 6$ & 39 & 21 & 11 & 12 & 566 & 450 \\
\hline M98F & $>1,000$ & 2.5 & $>1,000$ & $>1,000$ & $>1,000$ & $>1,000$ \\
\hline M301F & $>1,000$ & 0.59 & $>1,000$ & $>1,000$ & $>1,000$ & $>1,000$ \\
\hline M303F & $>1,000$ & 0.14 & $>1,000$ & $>1,000$ & $>1,000$ & $>1,000$ \\
\hline M304F & $>1,000$ & 0.50 & $>1,000$ & $>1,000$ & $>1,000$ & $>1,000$ \\
\hline M306F & $>1,000$ & 1.8 & $>1,000$ & $>1,000$ & $>1,000$ & $>1,000$ \\
\hline M307F & $>1,000$ & 0.75 & $>1,000$ & $>1,000$ & $>1,000$ & $>1,000$ \\
\hline M308F & $>1,000$ & 0.11 & $>1,000$ & $>1,000$ & $>1,000$ & $>1,000$ \\
\hline M332F & $>1,000$ & 5.4 & $>1,000$ & $>1,000$ & $>1,000$ & $>1,000$ \\
\hline M334F & $>1,000$ & 2.0 & $>1,000$ & $>1,000$ & $>1,000$ & $>1,000$ \\
\hline M336F & $>1,000$ & 213 & $>1,000$ & $>1,000$ & $>1,000$ & $>1,000$ \\
\hline M8ggsVI4 Q6E & $>1,000$ & 284 & 113 & 398 & 66 & 5.2 \\
\hline
\end{tabular}

a $1 \mathrm{mg} / \mathrm{F}$ FMDV antigen captured with $1 \mathrm{mg} / \mathrm{I}$ M311F.

${ }^{b} 1 \mathrm{mg} / \mathrm{I} \mathrm{FMDV}$ antigen captured with $1 \mathrm{mg} / \mathrm{I} \mathrm{M98F}$.

${ }^{\circ} 1 \mathrm{mg} / \mathrm{FMDV}$ antigen captured with $1 \mathrm{mg} / \mathrm{I} \mathrm{M8F}$.

${ }^{1} \mathrm{mg} / \mathrm{l} \mathrm{FMDV}$ antigen captured with $1 \mathrm{mg} / \mathrm{I} \mathrm{M170F}$.

${ }^{e}>1,000$, absorbance does not exceed 0.4 at the highest VHH concentration used (1 mg/l).

BFS, British Field Strain 1860; FMDV, foot-and-mouth disease virus; mAb, monoclonal antibody.

particles for panning, resulting in binding to capturing $\mathrm{VHH}$ and unwanted enrichment for $12 \mathrm{~S}$ binding phage clones. Since $12 \mathrm{~S}$ binding $\mathrm{VHHs}$ are generally not serotype specific this can be prevented by using $12 \mathrm{~S}$ particles from another strain for depletion in combination with a serotype-specific $\mathrm{VHH}$ for capturing $146 \mathrm{~S}$ particles. We currently favor this approach for isolation of 146S-specific VHHs. Selection of VHHs specifically recognizing Taenia solium antigen without cross-reacting with other Taenia species was earlier described (27). Furthermore, VHHs recognizing a recombinant immunotoxin without binding an undesired deamidated derivative of this immunotoxin were isolated recently (42). Together with our study these are further examples where the high functional diversity of camelid heavy-chain antibody immune libraries in combination with careful phage display selection schemes allows isolation of rare VHHs that can discriminate closely related antigens.

We developed two DAS ELISAs that utilize the same yeastproduced $\mathrm{VHH}$ for coating, as well as detection when in a biotinylated form, for quantification of FMDV $146 \mathrm{~S}$ particles. The ELISA with M379F VHH for quantification of SAT2 SAU/2/00 FMDV required 28 -fold higher $12 \mathrm{~S}$ concentrations than $146 \mathrm{~S}$ concentrations to reach similar absorbance values. Thus, it shows reasonable specificity for $146 \mathrm{~S}$ particles. However, it cannot be used for quantification of $146 \mathrm{~S}$ particles in the presence of high concentrations of $12 \mathrm{~S}$ particles due to cross-reaction with $12 \mathrm{~S}$ particles. Since the $12 \mathrm{~S}$ content of vaccines is generally less than $20 \%$ of total FMDV antigen (18), such specificity is sufficient to measure the $146 \mathrm{~S}$ content of SAT2 vaccines with only an about $1 \%$ error. Similar analyses performed with $\mathrm{M} 332 \mathrm{~F}$ VHH to quantify Asia 1 Shamir exhibited a 51-fold increase in specificity for $146 \mathrm{~S}$ particles, revealing this $\mathrm{VHH}$ could be used for $146 \mathrm{~S}$ quantification in the presence of high concentrations of $12 \mathrm{~S}$ particles. Both ELISAs showed an LOD of 2.3-4.6 $\mu \mathrm{g} / \mathrm{l} 146 \mathrm{~S}$. Assuming that the antigen concentration in FMDV vaccines is about $10 \mathrm{mg} / \mathrm{l}$ and that extraction of antigens from vaccines for use in VHH-ELISA involves a 10-fold dilution of vaccines (18), such sensitivity is amply sufficient for quantification of FMDV antigens in vaccines as well as stability studies of vaccines, which requires measurement of FMDV antigen concentrations that decrease to even lower levels. However, when needed for other applications the LOD could possibly be further increased by genetic fusion of $\mathrm{VHH}$ domains to increase affinity as was earlier demonstrated for an antitumor necrosis factor alpha VHH (43) and many further VHHs. In addition, both ELISAs did not detect strains belonging to other serotypes. The M332F ELISA also does not recognize strain Asia 1 Bahrain (results not shown). Both 146S-specific VHHs bind in a serotype-specific manner, and M332F binding is also strain specific. Such coincidence of strain and serotype specificity and $146 \mathrm{~S}$ specificity was observed before with the 146S-specific $\mathrm{O}_{1}$ Manisa binding VHH M170F (25) and two 146S-specific A serotype strain binding mAbs $(15,16)$. This suggests that the $146 \mathrm{~S}$-specific antigenic sites that we now detect on strains of O, SAT2, and Asia 1 serotypes are located on the same region of the FMDV capsid. This notion is consistent with the conservation of three of the four neutralizing antigenic sites between $\mathrm{O}, \mathrm{A}, \mathrm{C}$, and Asia 1 serotype FMDV strains (44). The $146 \mathrm{~S}$-specific antigenic site most likely overlaps with the interface of two $12 \mathrm{~S}$ pentamers. 


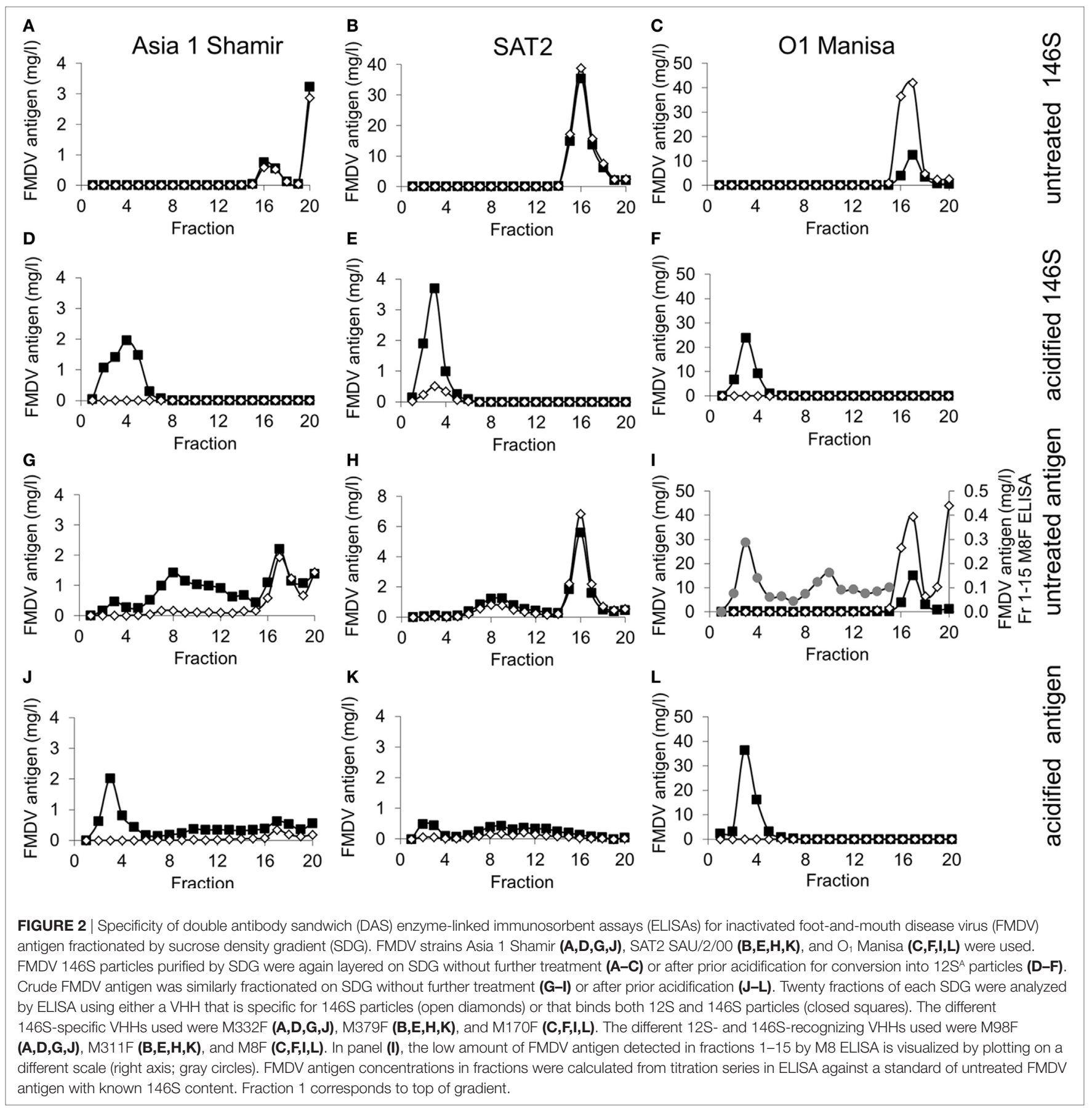

Double antibody sandwich enzyme-linked immunosorbent assay analysis of SDG fractionated inactivated FMDV antigen of strains SAT2 SAU/2/00, Asia 1 Shamir, and $\mathrm{O}_{1}$ Manisa reveals that some immunoreactive material fractionates between the $12 S$ and $146 \mathrm{~S}$ peaks (Figure 2). This material could represent $75 \mathrm{~S}$ empty capsids, although the peak is shallower compared to the $12 \mathrm{~S}$ and $146 \mathrm{~S}$ peaks, especially for strain Asia 1 Shamir. Consistent with this notion SDG fractionation of infectious Asia 1 Shamir and $\mathrm{O}_{1}$ Manisa FMDV confirms that this material is not infectious (Figure 3). These putative $75 \mathrm{~S}$ particles derived from inactivated antigen are not recognized by M170F, recognized with reduced efficiency by $\mathrm{M} 332 \mathrm{~F}$, and recognized well by M379F (Figure 2). Acidification of crude inactivated antigen did not fully convert the putative $75 \mathrm{~S}$ particles of strains SAT2 SAU/2/00 and Asia 1 Shamir and the 146S particles of strain Asia 1 Shamir into $12 \mathrm{~S}$ particles. We, therefore, recommend that preparation of a $12 \mathrm{~S}$ standard for use in the 12S-specific M3 ELISA is preferably done by SDG purification of $146 \mathrm{~S}$ particles and subsequent heating. The preparation of $12 \mathrm{~S}$ standards by conversion of $146 \mathrm{~S}$ present in crude antigen into $12 \mathrm{~S}$ as done 

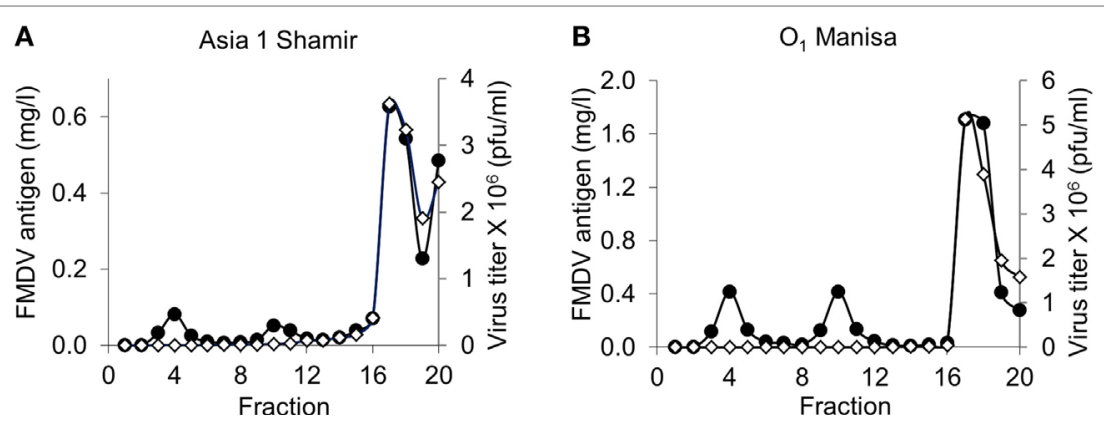

FIGURE 3 | Specificity of double antibody sandwich (DAS) enzyme-linked immunosorbent assays (ELISAs) for infectious foot-and-mouth disease virus (FMDV) particles fractionated by sucrose density gradient (SDG). Infectious virus of FMDV strain Asia 1 Shamir (A) or O, Manisa (B) was fractionated on SDG. Each fraction was analyzed for infectious FMDV titer (open diamonds) or the FMDV antigen concentration (closed circles). FMDV antigen concentration was measured by M3 ELISA on samples that were first acidified for conversion into $12 S^{A}$ particles against a $12 S^{A}$ standard. Fraction 1 corresponds to top of gradient.

earlier by us (17) is inaccurate as it ignores the $12 \mathrm{~S}$ particles already present in the sample and the $12 \mathrm{~S}$ particles derived from $75 \mathrm{~S}$ particles.

The ELISAs developed here for quantification of $146 \mathrm{~S}$ particles of strains Asia 1 Shamir and SAT2 SAU/2/00 can be used for quality control of FMD vaccines during and after manufacturing. There is a need for such quality control as many locally produced FMD vaccines show poor quality $(45,46)$. Several other ELISAs have been described recently for this purpose $(7,12-17)$. There are only three reports of ELISAs specific for $146 \mathrm{~S}$ particles (15-17). They were only suitable for $\mathrm{O}$ and A serotype strains. Our VHH-based ELISAs that detect $146 \mathrm{~S}$ particles of SAT2 and Asia 1 serotype strains thus complement the currently available 146S-specific ELISAs. The serotype and strain specificity of the VHHs are advantageous for independent quantification of different FMD strains in multivalent vaccines but has the disadvantage that their use is limited to the FMD strains recognized by these VHHs. The ELISAs developed here can also be used for analysis of FMDV stability in oil-adjuvanted vaccines as described earlier for $\mathrm{O}_{1}$ Manisa FMDV using the M170F ELISA $(17,18)$. As compared to the recently described thermofluor assay for measuring

\section{REFERENCES}

1. Paton DJ, Sumption KJ, Charleston B. Options for control of foot-and-mouth disease: knowledge, capability and policy. Philos Trans R Soc Lond B Biol Sci (2009) 364(1530):2657-67. doi:10.1098/rstb.2009.0100

2. Doel TR. Natural and vaccine induced immunity to FMD. Curr Top Microbiol Immunol (2005) 288:103-31. doi:10.1007/3-540-27109-0_5

3. Jamal SM, Belsham GJ. Foot-and-mouth disease: past, present and future. Vet Res (2013) 44:116. doi:10.1186/1297-9716-44-116

4. Brown F, Crick J. Application of agar-gel diffusion analysis to a study of the antigenic structure of inactivated vaccines prepared from the virus of footand-mouth disease. J Immunol (1959) 82(5):444-7.

5. Doel TR, Chong WK. Comparative immunogenicity of $146 \mathrm{~S}, 75 \mathrm{~S}$ and $12 \mathrm{~S}$ particles of foot-and-mouth disease virus. Arch Virol (1982) 73(2):185-91. doi:10.1007/BF01314726

6. Rao MG, Butchaiah G, Sen AK. Antibody response to $146 \mathrm{~S}$ particle, $12 \mathrm{~S}$ protein subunit and isolated VP1 polypeptide of foot-and-mouth disease virus type Asia-1. Vet Microbiol (1994) 39(1-2):135-43. doi:10.1016/ 0378-1135(94)90094-9
FMDV stability (47) our ELISAs have the advantage of increased sensitivity but disadvantage of strain specificity.

\section{ETHICS STATEMENT}

Llama immunizations were performed after ethical review by Wageningen Bioveterinary Research and in accordance with Dutch national guidelines on animal use.

\section{AUTHOR CONTRIBUTIONS}

$\mathrm{MH}$ and $\mathrm{EP}$ performed experiments. $\mathrm{MH}, \mathrm{JS}, \mathrm{PE}, \mathrm{BC}$, and $\mathrm{AD}$ conceived and designed experiments and analyzed data. $\mathrm{MH}$, JS, and $\mathrm{AD}$ wrote the manuscript. All the authors read and critically reviewed the manuscript.

\section{ACKNOWLEDGMENTS}

The authors want to thank Froukje van Hemert-Kluitenberg at Wageningen Bioveterinary Research for performing many experiments.

7. Seki C, Robiolo B, Periolo O, Iglesias M, D’Antuono A, Maradei E, et al. Rapid methodology for antigenic profiling of FMDV field strains and for the control of identity, purity and viral integrity in commercial virus vaccines using monoclonal antibodies. Vet Microbiol (2009) 133(3):239-51. doi:10.1016/j. vetmic.2008.07.011

8. Barteling SJ, Meloen RH. A simple method for the quantification of $140 \mathrm{~S}$ particles of foot-and-mouth disease virus (FMDV). Arch Gesamte Virusforsch (1974) 45(4):362-4. doi:10.1007/BF01242879

9. Spitteler MA, Fernandez I, Schabes E, Krimer A, Regulier EG, Guinzburg M, et al. Foot and mouth disease (FMD) virus: quantification of whole virus particles during the vaccine manufacturing process by size exclusion chromatography. Vaccine (2011) 29(41):7182-7. doi:10.1016/j. vaccine.2011.05.078

10. Yang Y, Li H, Li Z, Zhang Y, Zhang S, Chen Y, et al. Size-exclusion HPLC provides a simple, rapid, and versatile alternative method for quality control of vaccines by characterizing the assembly of antigens. Vaccine (2015) 33(9):1143-50. doi:10.1016/j.vaccine.2015.01.031

11. Yang M, Goolia M, Xu W, Bittner H, Clavijo A. Development of a quick and simple detection methodology for foot-and-mouth disease virus serotypes 
O, A and Asia 1 using a generic RapidAssay device. Virol J (2013) 10:125. doi:10.1186/1743-422X-10-125

12. Feng X, Ma JW, Sun SQ, Guo HC, Yang YM, Jin Y, et al. Quantitative detection of the foot-and-mouth disease virus serotype O 146S antigen for vaccine production using a double-antibody sandwich ELISA and nonlinear standard curves. PLoS One (2016) 11(3):e0149569. doi:10.1371/journal. pone. 0149569

13. Ma LN, Zhang J, Chen HT, Zhou JH, Ding YZ, Liu YS. An overview on ELISA techniques for FMD. Virol J (2011) 8:419. doi:10.1186/1743-422X-8-419

14. Morioka K, Fukai K, Yoshida K, Yamazoe R, Onozato H, Ohashi S, et al. Footand-mouth disease virus antigen detection enzyme-linked immunosorbent assay using multiserotype-reactive monoclonal antibodies. J Clin Microbiol (2009) 47(11):3663-8. doi:10.1128/JCM.00695-09

15. Van Maanen C, Terpstra C. Quantification of intact $146 \mathrm{~S}$ foot-and-mouth disease antigen for vaccine production by a double antibody sandwich ELISA using monoclonal antibodies. Biologicals (1990) 18(4):315-9. doi:10.1016/1045-1056(90)90036-Y

16. Yang M, Holland H, Clavijo A. Production of monoclonal antibodies against whole virus particles of foot-and-mouth disease virus serotype $\mathrm{O}$ and $\mathrm{A}$ and their potential use in quantification of intact virus for vaccine manufacture. Vaccine (2008) 26(27-28):3377-82. doi:10.1016/j.vaccine.2008. 04.062

17. Harmsen MM, Fijten HP, Westra DF, Coco-Martin JM. Effect of thiomersal on dissociation of intact (146S) foot-and-mouth disease virions into $12 \mathrm{~S}$ particles as assessed by novel ELISAs specific for either $146 \mathrm{~S}$ or $12 \mathrm{~S}$ particles. Vaccine (2011) 29(15):2682-90. doi:10.1016/j.vaccine.2011.01.069

18. Harmsen MM, Fijten HPD, Westra DF, Dekker A. Stabilizing effects of excipients on dissociation of intact (146S) foot-and-mouth disease virions into $12 \mathrm{~S}$ particles during storage as oil-emulsion vaccine. Vaccine (2015) 33:2477-84. doi:10.1016/j.vaccine.2015.03.066

19. Butchaiah G, Card JL, Morgan DO. Antigenic relationships of foot-andmouth disease virus serotype Asia-1 isolates demonstrated by monoclonal antibodies. Vet Immunol Immunopathol (1992) 30(2-3):275-92. doi:10.1016/0165-2427(92)90144-F

20. McCullough KC, Butcher R. Monoclonal antibodies against foot-and-mouth disease virus 146S and 12S particles. Arch Virol (1982) 74(1):1-9. doi:10.1007/ BF01320777

21. Pfaff E, Thiel HJ, Beck E, Strohmaier K, Schaller H. Analysis of neutralizing epitopes on foot-and-mouth disease virus. J Virol (1988) 62(6):2033-40.

22. Saiz JC, Gonzalez MJ, Morgan DO, Card JL, Sobrino F, Moore DM. Antigenic comparison of different foot-and-mouth disease virus types using monoclonal antibodies defining multiple neutralizing epitopes on FMDV A5 subtypes. Virus Res (1989) 13(1):45-60. doi:10.1016/0168-1702(89)90086-5

23. Wang D, Yang S, Yin S, Shang Y, Du P, Guo J, et al. Characterization of single-domain antibodies against foot and mouth disease virus (FMDV) serotype $\mathrm{O}$ from a camelid and imaging of FMDV in baby hamster kidney-21 cells with single-domain antibody-quantum dots probes. BMC Vet Res (2015) 11(1):120. doi:10.1186/s12917-015-0437-2

24. Yin S, Yang S, Shang Y, Sun S, Zhou G, Jin Y, et al. Characterization of Asia 1 sdAb from camels bactrianus (C. bactrianus) and conjugation with quantum dots for imaging FMDV in BHK-21 cells. PLoS One (2013) 8(5):e63500. doi:10.1371/journal.pone.0063500

25. Harmsen MM, Van Solt CB, Fijten HPD, Van Keulen L, Rosalia RA, Weerdmeester K, et al. Passive immunization of guinea-pigs with llama single-domain antibody fragments against foot-and-mouth disease. Vet Microbiol (2007) 120(3-4):193-206. doi:10.1016/j.vetmic.2006.10.029

26. Pardon E, Laeremans T, Triest S, Rasmussen SG, Wohlkonig A, Ruf A, et al. A general protocol for the generation of nanobodies for structural biology. Nat Protoc (2014) 9(3):674-93. doi:10.1038/nprot.2014.039

27. Deckers N, Saerens D, Kanobana K, Conrath K, Victor B, Wernery U, et al. Nanobodies, a promising tool for species-specific diagnosis of Taenia solium cysticercosis. Int J Parasitol (2009) 39(5):625-33. doi:10.1016/j. ijpara.2008.10.012

28. Even-Desrumeaux K, Nevoltris D, Lavaut MN, Alim K, Borg JP, Audebert S, et al. Masked selection: a straightforward and flexible approach for the selection of binders against specific epitopes and differentially expressed proteins by phage display. Mol Cell Proteomics (2014) 13(2):653-65. doi:10.1074/mcp. O112.025486
29. Hoogenboom HR, de Bruine AP, Hufton SE, Hoet RM, Arends JW, Roovers RC. Antibody phage display technology and its applications. Immunotechnology (1998) 4(1):1-20. doi:10.1016/S1380-2933(98)00007-4

30. Freiberg B, Hohlich B, Haas B, Saalmuller A, Pfaff E, Marquardt O. Typeindependent detection of foot-and-mouth disease virus by monoclonal antibodies that bind to amino-terminal residues of capsid protein VP2.J Virol Methods (2001) 92(2):199-205. doi:10.1016/S0166-0934(00)00287-1

31. Harmsen MM, Fijten HPD. Improved functional immobilization of llama single-domain antibody fragments to polystyrene surfaces using small peptides. J Immunoassay Immunochem (2012) 33(3):234-51. doi:10.1080/15321 819.2011.634473

32. Harmsen MM, Fijten HPD, Dekker A, Eblé PL. Passive immunization of pigs with bispecific llama single-domain antibody fragments against foot-andmouth disease and porcine immunoglobulin. Vet Microbiol (2008) 132:56-64. doi:10.1016/j.vetmic.2008.04.030

33. Harmsen MM, Jansen J, Westra DF, Coco-Martin JM. Characterization of foot-and-mouth disease virus antigen by surface-enhanced laser desorption ionization-time of flight-mass spectrometry in aqueous and oil-emulsion formulations. Vaccine (2010) 28(19):3363-70. doi:10.1016/j.vaccine.2010.02.084

34. Harmsen MM, Blokker JC, Pritz-Verschuren SB, Bartelink W, Van der Burg H, Koch G. Isolation of panels of llama single-domain antibody fragments binding all nine neuraminidase subtypes of influenza A virus. Antibodies (2013) 2:168-92. doi:10.3390/antib2020168

35. Harmsen MM, Van Solt CB, Fijten HPD, Van Setten MC. Prolonged in vivo residence times of llama single-domain antibody fragments in pigs by binding to porcine immunoglobulins. Vaccine (2005) 23(41):4926-34. doi:10.1016/j. vaccine.2005.05.017

36. McCafferty J, Johnson KS. Construction and screening of antibody display libraries. In: Kay BK, Winter J, McCafferty J, editors. Phage Display of Peptides and Proteins. San Diego: Academic Press (1996). p. 79-111.

37. Harmsen MM, Ruuls RC, Nijman IJ, Niewold TA, Frenken LGJ, de Geus B. Llama heavy-chain $\mathrm{V}$ regions consist of at least four distinct subfamilies revealing novel sequence features. Mol Immunol (2000) 37(10):579-90. doi:10.1016/S0161-5890(00)00081-X

38. Lefranc MP, Pommie C, Ruiz M, Giudicelli V, Foulquier E, Truong L, et al. IMGT unique numbering for immunoglobulin and $\mathrm{T}$ cell receptor variable domains and Ig superfamily V-like domains. Dev Comp Immunol (2003) 27(1):55-77. doi:10.1016/S0145-305X(02)00039-3

39. Butler JE, Ni L, Nessler R, Joshi KS, Suter M, Rosenberg B, et al. The physical and functional behavior of capture antibodies adsorbed on polystyrene. J Immunol Methods (1992) 150(1-2):77-90. doi:10.1016/00221759(92)90066-3

40. McCullough KC, Crowther JR, Butcher RN. Alteration in antibody reactivity with foot-and-mouth disease virus (FMDV) $146 \mathrm{~S}$ antigen before and after binding to a solid phase or complexing with specific antibody. J Immunol Methods (1985) 82(1):91-100. doi:10.1016/0022-1759(85)90228-5

41. Ellard FM, Drew J, Blakemore WE, Stuart DI, King AM. Evidence for the role of His-142 of protein 1C in the acid-induced disassembly of foot-andmouth disease virus capsids. J Gen Virol (1999) 80(8):1911-8. doi:10.1099/ 0022-1317-80-8-1911

42. Pabst TM, Wendeler M, Wang X, Bezemer S, Hermans P, Hunter AK. Camelid VHH affinity ligands enable separation of closely related biopharmaceuticals. Biotechnol J (2017) 12(2):1600357. doi:10.1002/biot.201600357

43. Coppieters K, Dreier T, Silence K, de Haard H, Lauwereys M, Casteels P, et al. Formatted anti-tumor necrosis factor alpha VHH proteins derived from camelids show superior potency and targeting to inflamed joints in a murine model of collagen-induced arthritis. Arthritis Rheum (2006) 54(6):1856-66. doi:10.1002/art.21827

44. Grazioli S, Fallacara F, Brocchi E. Mapping of antigenic sites of foot-andmouth disease virus serotype Asia 1 and relationships with sites described in other serotypes. JGen Virol (2013) 94(3):559-69. doi:10.1099/vir.0. 048249-0

45. Jamal SM, Shah SI, Ali Q, Mehmood A, Afzal M, Afzal M, et al. Proper quality control of formulated foot-and-mouth disease vaccines in countries with prophylactic vaccination is necessary. Transbound Emerg Dis (2014) 61(6):483-9. doi:10.1111/tbed.12051

46. Robinson L, Knight-Jones TJ, Charleston B, Rodriguez LL, Gay CG, Sumption KJ, et al. Global foot-and-mouth disease research update and 
gap analysis: 3 - vaccines. Transbound Emerg Dis (2016) 63(S1):30-41. doi:10.1111/tbed.12518

47. Kotecha A, Zhang F, Juleff N, Jackson T, Perez E, Stuart D, et al. Application of the thermofluor PaSTRy technique for improving foot-and-mouth disease virus vaccine formulation. J Gen Virol (2016) 97(7):1557-65. doi:10.1099/ jgv.0.000462

Conflict of Interest Statement: The authors declare that the research was conducted in the absence of any commercial or financial relationships that could be construed as a potential conflict of interest.
The reviewer, MG, and handling editor declared their shared affiliation, and the handling editor states that the process nevertheless met the standards of a fair and objective review.

Copyright (๑) 2017 Harmsen, Seago, Perez, Charleston, Eblé and Dekker. This is an open-access article distributed under the terms of the Creative Commons Attribution License (CC BY). The use, distribution or reproduction in other forums is permitted, provided the original author(s) or licensor are credited and that the original publication in this journal is cited, in accordance with accepted academic practice. No use, distribution or reproduction is permitted which does not comply with these terms. 